\title{
Clinical similarities and differences of patients with X-linked lymphoproliferative syndrome type 1 (XLP-1/SAP deficiency) versus type 2 (XLP-2/XIAP deficiency)
}

\author{
Pachlopnik Schmid, Jana ; Canioni, D ; Moshous, D ; et al
}

\begin{abstract}
X-linked lymphoproliferative syndromes (XLP) are primary immunodeficiencies characterized by a particular vulnerability toward Epstein-Barr virus infection, frequently resulting in hemophagocytic lymphohistiocytosis (HLH). XLP type 1 (XLP-1) is caused by mutations in the gene SH2D1A (also named SAP), whereas mutations in the gene XIAP underlie XLP type 2 (XLP-2). Here, a comparison of the clinical phenotypes associated with XLP-1 and XLP-2 was performed in cohorts of 33 and 30 patients, respectively. HLH (XLP-1, 55\%; XLP-2, 76\%) and hypogammaglobulinemia (XLP-1, 67\%; XLP-2, $33 \%)$ occurred in both groups. Epstein-Barr virus infection in XLP-1 and XLP-2 was the common trigger of HLH (XLP-1, 92\%; XLP-2, 83\%). Survival rates and mean ages at the first HLH episode did not differ for both groups, but HLH was more severe with lethal outcome in XLP-1 (XLP-1, 61\%; XLP-2, 23\%). Although only XLP-1 patients developed lymphomas (30\%), XLP-2 patients (17\%) had chronic hemorrhagic colitis as documented by histopathology. Recurrent splenomegaly often associated with cytopenia and fever was preferentially observed in XLP-2 (XLP-1, 7\%; XLP-2, 87\%) and probably represents minimal forms of HLH as documented by histopathology. This first phenotypic comparison of XLP subtypes should help to improve the diagnosis and the care of patients with XLP conditions.
\end{abstract}

DOI: https://doi.org/10.1182/blood-2010-07-298372

Posted at the Zurich Open Repository and Archive, University of Zurich ZORA URL: https://doi.org/10.5167/uzh-58393

Journal Article

Published Version

Originally published at:

Pachlopnik Schmid, Jana; Canioni, D; Moshous, D; et al (2011). Clinical similarities and differences of patients with X-linked lymphoproliferative syndrome type 1 (XLP-1/SAP deficiency) versus type 2 (XLP-2/XIAP deficiency). Blood, 117(5):1522-1529.

DOI: https://doi.org/10.1182/blood-2010-07-298372 


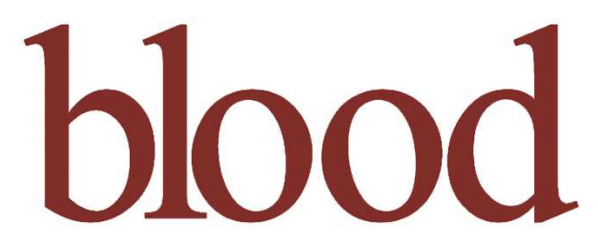

2011 117: 1522-1529

Prepublished online November 30, 2010;

doi:10.1182/blood-2010-07-298372

\section{Clinical similarities and differences of patients with X-linked lymphoproliferative syndrome type 1 (XLP-1/SAP deficiency) versus type 2 (XLP-2/XIAP deficiency)}

Jana Pachlopnik Schmid, Danielle Canioni, Despina Moshous, Fabien Touzot, Nizar Mahlaoui, Fabian Hauck, Hirokazu Kanegane, Eduardo Lopez-Granados, Ester Mejstrikova, Isabelle Pellier, Lionel Galicier, Claire Galambrun, Vincent Barlogis, Pierre Bordigoni, Alain Fourmaintraux, Mohamed Hamidou, Alain Dabadie, Françoise Le Deist, Filomeen Haerynck, Marie Ouachée-Chardin, Pierre Rohrlich, Jean-Louis Stephan, Christelle Lenoir, Stéphanie Rigaud, Nathalie Lambert, Michèle Milili, Claudin Schiff, Helen Chapel, Capucine Picard, Geneviève de Saint Basile, Stéphane Blanche, Alain Fischer and Sylvain Latour

Updated information and services can be found at:

http://bloodjournal.hematologylibrary.org/content/117/5/1522.full.html

Articles on similar topics can be found in the following Blood collections

Immunobiology (4451 articles)

Lymphoid Neoplasia (3 articles)

Clinical Trials and Observations (3161 articles)

Information about reproducing this article in parts or in its entirety may be found online at:

http://bloodjournal.hematologylibrary.org/site/misc/rights.xhtml\#repub_requests

Information about ordering reprints may be found online at:

http://bloodjournal.hematologylibrary.org/site/misc/rights.xhtml\#reprints

Information about subscriptions and ASH membership may be found online at: http://bloodjournal.hematologylibrary.org/site/subscriptions/index.xhtml

Blood (print ISSN 0006-4971, online ISSN 1528-0020), is published weekly by the American Society of Hematology, 2021 L St, NW, Suite 900,

Washington DC 20036.

Copyright 2011 by The American Society of Hematology; all rights reserved.

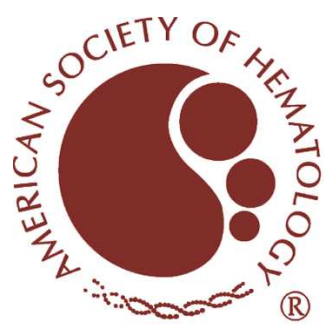




\title{
Clinical similarities and differences of patients with X-linked lymphoproliferative syndrome type 1 (XLP-1/SAP deficiency) versus type 2 (XLP-2/XIAP deficiency)
}

\begin{abstract}
Jana Pachlopnik Schmid, ${ }^{1-3}$ Danielle Canioni, ${ }^{4}$ Despina Moshous, ${ }^{1-3}$ Fabien Touzot, ${ }^{3}$ Nizar Mahlaoui, ${ }^{3}$ Fabian Hauck,,${ }^{1,2}$ Hirokazu Kanegane, ${ }^{5}$ Eduardo Lopez-Granados, ${ }^{6}$ Ester Mejstrikova, ${ }^{7}$ Isabelle Pellier, ${ }^{8,9}$ Lionel Galicier, ${ }^{10}$ Claire Galambrun, ${ }^{11}$ Vincent Barlogis, ${ }^{11}$ Pierre Bordigoni, ${ }^{12}$ Alain Fourmaintraux, ${ }^{13}$ Mohamed Hamidou, ${ }^{14}$ Alain Dabadie, ${ }^{15}$ Françoise Le Deist, ${ }^{16}$ Filomeen Haerynck, ${ }^{17}$ Marie Ouachée-Chardin, ${ }^{18}$ Pierre Rohrlich, ${ }^{19-21}$ Jean-Louis Stephan, ${ }^{22}$ Christelle Lenoir, ${ }^{1}$ Stéphanie Rigaud, ${ }^{1,2}$ Nathalie Lambert, ${ }^{1,23}$ Michèle Milili, ${ }^{24}$ Claudin Schiff, ${ }^{24}$ Helen Chapel, ${ }^{6}$ Capucine Picard, ${ }^{2,23,25}$ Geneviève de Saint Basile, ${ }^{1-3}$ Stéphane Blanche, ${ }^{3}$ Alain Fischer, ${ }^{1-3}$ and Sylvain Latour ${ }^{1,2}$

${ }^{1}$ Inserm Unité 768, Laboratoire du Développement Normal et Pathologique du Système Immunitaire, Hôpital Necker-Enfants Malades, Paris, France; ²Université Paris Descartes, Institut Fédératif de Recherche Necker Enfants-Malades (IFR94), Paris, France; 3Unité d'Immunologie et Hématologie Pédiatrique, Assistance Publique-Hôpitaux de Paris (AP-HP), Hôpital Necker Enfants-Malades, Paris, France; ${ }^{4}$ Service d'Anatomie et de Cytologie Pathologiques, AP-HP, Hôpital Necker Enfants-Malades, Paris, France; ${ }^{5}$ Department of Pediatrics, Graduate School of Medicine, University of Toyama, Toyama, Japan; ${ }^{6}$ Department of Clinical Immunology, Nuffield Department of Medicine, University of Oxford, Oxford, United Kingdom; ${ }^{7}$ Department of Pediatric Hematology and Oncology, Teaching Hospital Motol and 2nd Medical School, Charles University, Prague, Czech Republic; 'Unité d'Hématologie-Immunologie-Oncologie Pédiatrique, Centre Hospitalier Universitaire (CHU) Angers, Angers, France; 9 Inserm Unité 892, Centre de Recherche en Cancérologie Nantes-Angers, Nantes, France; ${ }^{10}$ Service Immuno-Hématologie, AP-HP, Hôpital Saint-Louis, Paris, France; ${ }^{11}$ Service d'Hématologie Pédiatrique, Hôpital Timone Enfants, Marseille, France;

${ }^{12}$ Departement d'Hémato-Oncologie Pediatrique et de Transplantation Medullaire, CHU Nancy, Vandoeuvre, France; ${ }^{13}$ Service de Néonatologie, Groupe Hospitalier Sud Réunion, Saint Pierre, La Réunion, France; ${ }^{14}$ Médecine Interne, CHU Nantes, Nantes, France; ${ }^{15}$ Service de Hépato-Gastro-Entérologie, CHU Rennes, Rennes, France; ${ }^{16}$ Département de Microbiologie et d'Immunologie, et Département de Pédiatrie, Université de Montréal, CHU Sainte-Justine, Montréal, QC; ${ }^{17}$ Département of Child Immunology, Ghent University Hospital, Ghent, Belgium; ${ }^{18}$ Service d'Hématologie, AP-HP, CHU Hôpital Robert Debré, Paris, France; ${ }^{19}$ Inserm UMR645, Besançon, France; ${ }^{20}$ Université Franche-Comté, Besançon, France; ${ }^{21}$ Service de Pédiatrie, CHU Besançon, Besançon, France; ${ }^{22}$ Unite d'Hématologie et Oncologie Pédiatrique, Hôpital Nord, CHU Saint-Etienne, Saint-Etienne, France; ${ }^{23} \mathrm{Centre} \mathrm{d'Etude} \mathrm{des} \mathrm{Déficits} \mathrm{Immunitaires,}$ Hôpital Necker-Enfants Malades, Paris, France; ${ }^{24}$ Centre d'é3 ${ }^{1}$ Centre d'Immunologie de Marseille-Luminy, Parc Scientifique de Luminy-Case 906, Marseille, France; and ${ }^{25}$ Inserm Unité 980, GHMI, Hôpital Necker Enfants-Malades, Paris, France
\end{abstract}

X-linked lymphoproliferative syndromes (XLP) are primary immunodeficiencies characterized by a particular vulnerability toward Epstein-Barr virus infection, frequently resulting in hemophagocytic lymphohistiocytosis (HLH). XLP type 1 (XLP-1) is caused by mutations in the gene SH2D1A (also named SAP), whereas mutations in the gene XIAP underlie XLP type 2 (XLP-2). Here, a comparison of the clinical phenotypes associated with XLP-1 and XLP-2 was performed in cohorts of 33 and 30 patients, respectively. HLH (XLP-1, $55 \%$; XLP-2, 76\%) and hypogammaglobulinemia (XLP-1, 67\%; XLP-2, 33\%) occurred in both groups. Epstein-Barr virus infection in XLP-1 and XLP-2 was the common trigger of HLH (XLP-1, 92\%; XLP-2, 83\%). Survival rates and mean ages at the first HLH episode did not differ for both groups, but HLH was more severe with lethal outcome in XLP-1 (XLP-1, 61\%; XLP-2, 23\%). Although only XLP-1 patients developed lymphomas
(30\%), XLP-2 patients (17\%) had chronic hemorrhagic colitis as documented by histopathology. Recurrent splenomegaly often associated with cytopenia and fever was preferentially observed in XLP-2 (XLP-1, 7\%; XLP-2, 87\%) and probably represents minimal forms of $\mathrm{HLH}$ as documented by histopathology. This first phenotypic comparison of XLP subtypes should help to improve the diagnosis and the care of patients with XLP conditions. (Blood. 2011;117(5):1522-1529)

\section{Introduction}

$\mathrm{X}$-linked lymphoproliferative syndrome (XLP) is a rare immunodeficiency condition characterized by an extreme vulnerability to Epstein-Barr virus (EBV) infection, frequently resulting in hemophagocytic lymphohistiocytosis (HLH) or virus-associated hemophagocytic syndrome (VAHS). ${ }^{1-3} \mathrm{HLH}$ is caused by overwhelming T-cell and macrophage activation, leading to fever, splenomegaly, cytopenia, hypofibrinogenemia, or hypertriglyceridemia, hyperferritinemia, and hemophagocytosis. ${ }^{4}$

XLP belongs to the group of familial hemophagocytic lymphohistiocytosis (FHL) as originally proposed by Purtilo et al. ${ }^{1}$ In the original description, the term "lymphoproliferative disease" in the
Duncan kindred ${ }^{1}$ was used for benign or malignant lymphoproliferation but also for the diffuse organ "infiltrates composed of lymphocytes, plasma cells, and histiocytes, some containing erythrocytes," describing histologic features of HLH. Thus, the term "X-linked lymphoproliferative disease or syndrome" used thereafter to name this condition refers not only to malignant lymphomas but also to HLH. Two genetic causes are responsible for XLP. XLP type 1 (XLP-1) is caused by hemizygous mutations in the gene SH2D1A encoding the signaling lymphocyte activation molecule (SLAM)-associated protein (SAP) (MIM no. 308240). ${ }^{5,6}$ Hemizygous mutations in the gene encoding the $\mathrm{X}$-linked inhibitor of
Submitted July 26, 2010; accepted October 18, 2010. Prepublished online as Blood First Edition paper, November 30, 2010; DOI 10.1182/blood-2010-07-298372.
The publication costs of this article were defrayed in part by page charge payment. Therefore, and solely to indicate this fact, this article is hereby marked "advertisement" in accordance with 18 USC section 1734. 
apoptosis protein (XIAP; also termed BIRC4; MIM no. 300635) have been discovered in a cohort of patients with clinical XLP without any identified mutations in SH2D1A and normal SAP protein expression. ${ }^{7}$ Thus, mutations in XIAP define the XLP type 2 (XLP-2). These findings were confirmed by the identification of additional patients with XIAP deficiency. ${ }^{8,9}$ After EBV infection in most (but not all) cases, patients bearing mutations in SH2D1A (hereafter denoted SAP-deficient patients) may experience variable manifestations such as fulminant infectious mononucleosis corresponding pathophysiologically to HLH, malignant lymphoma, and hypogammaglobulinemia. ${ }^{2,10,11}$ Less common findings are dysgammaglobulinemia, bone marrow hypoplasia, especially aplastic anemia, and lymphocytic vasculitis. ${ }^{12,13}$ However, although HLH is almost always triggered by $\mathrm{EBV}$, the other manifestations can be present even in SAPdeficient patients who have never encountered EBV. ${ }^{2,3,10,11}$ The clinical features of the 12 patients with mutations in XIAP (hereafter denoted XIAP-deficient patients) initially described, slightly differed from the features described above. In some XIAP-deficient patients, splenomegaly was noticed as the first clinical symptom, and chronic colitis occurred during the disease course in 2 patients. ${ }^{7}$

The gene product affected in XLP-1 patients, SAP, is a small $\mathrm{SH} 2$-containing adaptor protein that is expressed in $\mathrm{T}$, natural killer (NK), and invariant NKT (iNKT) cells. ${ }^{5,14}$ SAP binds with high affinity and specificity to tyrosine-based motifs located in the cytoplasmic domains of the transmembrane receptors of the SLAM family. SAP couples SLAM family receptors to downstream signaling pathways and thereby enables SLAM receptors to mediate an array of activating or regulatory signals. In SAPdeficient humans and mice, multiple cellular defects have been documented, including altered $\mathrm{CD}^{+} \mathrm{T}$ - and NK-cell cytotoxicity responses, $\mathrm{CD}^{+}{ }^{+} \mathrm{T}$ helper cell cytokine production and function, block of CD1d-restricted iNKT-cell development, defective antibody production associated with reduced numbers of switched memory B cells and defects in germinal center formation. ${ }^{11,14}$ Studies of SAP-deficient humans and mice support the notion that the immune dysfunctions seen in SAP-deficiency are mostly caused by alterations in the signal transduction of SLAM family receptors.

The XLP-2 gene product, XIAP, belongs to the family of inhibitor of apoptosis proteins and is well known to be a potent physiologic inhibitor of caspases 3,7 , and $9 .{ }^{15}$ XIAP is ubiquitously expressed. ${ }^{7}$ In addition to its antiapoptotic role, XIAP is also involved in multiple signaling pathways, including copper metabolism, activation of the nuclear factor $\kappa \mathrm{B}$ and the mitogen-activated protein kinases pathways and the transforming growth factor- $\beta$ receptor and bone morphogenetic protein-receptor signal transduction. ${ }^{16}$ In XIAP-deficient patients, lymphocytes are characterized by an increased susceptibility to apoptosis in response to CD95 and tumor necrosis factor receptor-related apoptosis-inducing ligand receptor stimulation as well as enhanced activation-induced cell death. ${ }^{7}$ XIAP-deficient patients also display low but detectable numbers of iNKT cells in blood although a recent study indicated that they can have normal numbers of iNKT cells. ${ }^{9}$ NK cellmediated cytotoxicity is apparently normal in XIAP-deficient patients. ${ }^{7,9}$

Our knowledge of the immune dysfunctions underlying the clinical manifestations in SAP-deficient patients has been largely improved in the past decade. However, this is not the case for XIAP-deficient patients. A better characterization of the clinical similarities and the differences between XLP-1 and XLP-2 could provide hints for a better understanding of the pathogenesis of these conditions and, furthermore, improve diagnostic and therapeutic procedures for these patients. Therefore, we performed a retrospective analysis of the clinical features observed in cohorts of 33 SAPand 30 XIAP-deficient patients.

\section{Methods}

\section{Patients and diagnosis}

We performed a retrospective analysis of the clinical and laboratory features of SAP- and XIAP-deficient patients in whom confirmative molecular diagnosis had been performed at the Necker Children's Hospital. Patient conditions were diagnosed as XLP-1 and XLP-2 on the basis of molecular results or on the basis of clinical features when disease had been molecularly proven in male relatives on the mother's side (supplemental Methods and Results, available on the Blood Web site; see the Supplemental Materials link at the top of the online article). Patients and families provided informed consent for genetic and immunologic studies in accordance to the 1975 Declaration of Helsinki, and the study was approved by the local ethics regulations (Necker-Enfants Malades Ethical Board Committee).

\section{Protein expression}

Expression of SAP and XIAP was analyzed by Western blotting or flow cytometry or both after intracellular staining in phytohemagglutinininduced T-cell blasts or peripheral blood mononuclear cells or both as described. ${ }^{7}$ The monoclonal antibody $(\mathrm{mAb})$ anti-SAP was kindly provided by $\operatorname{Dr}$ A. Veillette, IRCM, Montréal. Intracellular SAP was stained by fluorescein isothiocyanate- or phycoerythrin-coupled anti-SAP mAb and XIAP detected with noncoupled anti-XIAP mouse mAb (clone 48; BD Biosciences) revealed with fluorescein isothiocyanate-coupled antimouse antibodies (Jackson ImmunoResearch Laboratories Inc) after cell permeabilization with Perm 2 (BD Biosciences).

\section{Histology and immunohistochemistry}

All diagnostic specimens were fixed in $10 \%$ buffered formalin and stained with hematoxylin and eosin, Giemsa, or trichrome dyes (for the liver). Immunohistochemistry was performed on fixed tissues with a peroxidasebased method (Dako). Antibodies used were raised against CD20, CD3, CD8, and latent membrane protein 1 (LMP-1) (Dako); CD25 (Novocastra); and T-cell intracellular antigen-1 (Immunotech). EVB-encoded RNA (EBER) was probed on some specimen with the use of in situ hybridization technique. Slides were observed using a Leica DM LB microscope with $\times 20, \times 40$, and $\times 100$ objectives and a $10 \times$ eyepiece. Acquisition of images was with IM50 software (Leica Microsystems). All slides were analyzed by the same pathologist (D.C.), and an independent review was also performed (F.H.).

\section{Clinical assessment}

The patients' clinical events and laboratory features were assessed retrospectively by retrieval of data from medical records.

\section{Statistical analysis}

The statistical analyses were performed with Fisher exact tests or log-rank tests (for comparison of survival curves) with the use of the PRISM software (GraphPad Software Inc).

\section{Results}

XLP-1 was diagnosed in 33 patients from 19 families, and mutations of SH2D1A were found in 18 families, and XLP-2 was 
From bloodjournal.hematologylibrary.org at UNIVERSITAETSSPITAL on May 30, 2011. For personal use only.

Table 1. Characteristics of patients with mutations in SH2D1A/SAP (XLP-1)

\begin{tabular}{|c|c|c|c|c|c|c|c|c|c|c|}
\hline $\begin{array}{l}\text { Patient } \\
\text { ID* }^{\star}\end{array}$ & $\begin{array}{c}\text { SH2D1A/SAP } \\
\text { mutation }\end{array}$ & $\begin{array}{l}\text { SAP } \\
\text { protein }\end{array}$ & $\begin{array}{l}\text { HLH (age in } \\
\text { years at } \\
\text { diagnosis) }\end{array}$ & $\begin{array}{l}\text { EBV at } \\
\text { first HLH }\end{array}$ & $\begin{array}{l}\text { HLH } \\
\text { relapses } \\
\text { (age in } \\
\text { years at } \\
\text { relapse) }\end{array}$ & $\begin{array}{c}\text { SM (age in } \\
\text { years at } \\
\text { diagnosis) }\end{array}$ & $\begin{array}{c}\text { Hypo- } \gamma \text { (age in } \\
\text { years at } \\
\text { diagnosis) }\end{array}$ & $\begin{array}{l}\text { Lymphoma } \\
\text { (age in } \\
\text { years at } \\
\text { diagnosis) }\end{array}$ & $\begin{array}{c}\text { Other } \\
\text { manifestations } \\
\text { (age in years at } \\
\text { diagnosis) }\end{array}$ & Outcome (age in years) \\
\hline S1.1 & E67G & & - & NA & & - & - & 13 & - & Alive, well (19) \\
\hline S1.2 & E67G & - & 3 & + & $+(25)$ & - & $+(26)$ & 34 & - & $\begin{array}{l}\text { Alive, under lymphoma } \\
\text { treatment (34) }\end{array}$ \\
\hline S1.3 & E67G & & 15 & $?$ & - & - & - & 7,30 & - & $\begin{array}{l}\text { Alive, under lymphoma } \\
\text { treatment (30) }\end{array}$ \\
\hline S1.4 & E67G & & - & NA & & - & $+(4) \dagger$ & - & - & Alive, well, IVIG (10) \\
\hline S2.1 I & 196X & - & 4 & $?$ & - & ? & ? & - & - & Died $(4, \mathrm{HLH})$ \\
\hline S3.1 & del. of exons 1-4 & & - & NA & & - & $+\dagger$ & - & Chronic gastritis, & Alive, well, IVIG (20) \\
\hline S3.2 & del. of exons $1-4$ & & - & NA & & - & $+\dagger$ & - & $\begin{array}{l}\text { IM (2), chronic } \\
\text { gastritis }\end{array}$ & Alive, well, IVIG (20) \\
\hline S4.1 & R55X & & - & NA & & - & - & 40 & - & Alive, well (42) \\
\hline S4.2 I & ND & & 6 & + & - & - & - & - & - & Died (6, HLH) \\
\hline S5.1 & del. of exon 2 & & 3.7 & + & - & ? & ? & - & - & Died $(3.7, \mathrm{HLH})$ \\
\hline S5.2 & ND & & - & NA & & - & ? & 5 & - & Died (5, Iymphoma) \\
\hline S6.1 & del. of exon 1 & & 2.2 & + & - & - & ? & - & - & Died (2.2, HLH) \\
\hline S7.1 & R55X & - & 2.5 & + & - & - & ? & - & $\begin{array}{l}\text { Recurrent } \\
\text { infections }\end{array}$ & HSCT (2.7), alive (11) \\
\hline S8.1 > & X129RfsX141 & - & 2.4 & + & $+(9)$ & - & $+(3) \dagger$ & - & - & $\begin{array}{l}\text { First HSCT (9); second HSCT } \\
\text { (10); died (10.2) }\end{array}$ \\
\hline S8.2 & ND & & 2 & + & - & - & ? & - & - & Died $(2, \mathrm{HLH})$ \\
\hline S9.1 & $\mathrm{C} 42 \mathrm{Y}$ & $+1-$ & - & NA & & - & - & 2 & - & Alive (18) \\
\hline S9.2 & $\mathrm{C} 42 \mathrm{Y}$ & & - & NA & & - & $+(1) \dagger$ & - & - & Alive, well, IVIG (16) \\
\hline S10.1 & R55Q & & 14 & $?$ & - & ? & ? & - & - & $\operatorname{Died}(14, \mathrm{HLH})$ \\
\hline S11.1 > & $\mathrm{X} 129 \mathrm{R}$ fs X141 & - & - & NA & & - & + & - & - & Alive, well, N+T, IVIG (22) \\
\hline $\mathrm{S} 11.2>$ & $\mathrm{X} 129 \mathrm{R}$ fsX141 & & - & NA & & $?$ & $?$ & - & $\begin{array}{l}\text { Recurrent } \\
\text { pneumonia }\end{array}$ & Alive, well (66) \\
\hline S11.3 $>$ & $\mathrm{X} 129 \mathrm{R}$ fs X141 & & - & NA & & - & + & - & - & Alive, well, IVIG (15) \\
\hline S11.4 > & $\mathrm{X} 129 \mathrm{R}$ fsX141 & & - & NA & & - & $+(9)$ & 7 & - & Alive, well, IVIG (19) \\
\hline S12.1 & del. of exon 3 & - & 19 & + & - & - & $+(10) \dagger$ & 11 & $\mathrm{~T}(22)$ & Alive, T, IVIG (23) \\
\hline $\mathrm{S} 12.2$ & del. of exon 3 & & 19 & ? & - & - & $+(19) \dagger$ & 20 & - & Died (21, lymphoma) \\
\hline S13.1 & N82FfsX103 & ND & $10 \S$ & - & $+\left(12, \mathrm{EBV}^{+}\right)$ & $+(9) \ddagger$ & $?$ & - & - & Died (12, HLH) \\
\hline S14.1 & del. of exons 1-4 & & 3.5 & + & - & - & - & - & HUS (3.5) & Died (3.6, HLH) \\
\hline S15.1 & A22P & - & - & NA & & - & $+(13) \dagger$ & - & - & Alive, well, IVIG (25) \\
\hline S15.2 & ND & & 3.6 & $?$ & - & - & ? & - & - & Died $(3.6, \mathrm{HLH})$ \\
\hline S15.3 & ND & & - & NA & & $+(45) \ddagger$ & $?$ & - & - & Died (69, myelodysplasia) \\
\hline S16.1 & del. of exons 2-4 & - & 3.1 & + & - & - & ? & - & - & Died $(3.1, \mathrm{HLH})$ \\
\hline S17.1 I & M1T & - & - & NA & - & - & $+(4) \dagger$ & - & IM (2.4) & Alive, N+T, IVIG (20) \\
\hline S18.1 I & No mutation & - & $16 \S$ & $?$ & - & - & $+(15) \dagger$ & 9 & - & Died (17, HLH) \\
\hline S19.1 & del. of exons $1-4$ & - & 3.3 & + & & - & - & - & $\begin{array}{l}\text { Hypopigmented } \\
\text { hair }\end{array}$ & HSCT (3.7), died (3.8) \\
\hline
\end{tabular}

SM indicates recurrent splenomegaly or hepatosplenomegaly; Hypo- $\gamma$, hypogammaglobulinemia; NA, not applicable; del., deletion; ?, unknown; IM, infectious mononucleosis; ND, not done; HSCT, hematopoietic stem cell transplantation; N, neutropenia; T, thrombocytopenia; and HUS, hemolytic uremic syndrome.

*Patient identification: $S$ indicates SAP-deficiency, the first number corresponds to the family and the second to the individual patient.

tWith recurrent respiratory infections; + indicates yes or positive; -, no or negative.

‡Recurrent splenomegaly or hepatosplenomegaly associated with intermittent fever, anemia, and cytopenia.

§Diagnosed as incomplete HLH.

diagnosed in 30 patients from 11 families (Tables 1 and 2). In one patient (PS18.1), no mutation in SH2D1A was found; however, no SAP protein expression was detected. ${ }^{17}$ Six and 7 mutations in SH2D1A and XIAP were novel and not reported, respectively (supplemental Methods and Results).

Clinical manifestations included HLH, splenomegaly and incomplete forms of HLH, lymphoma, dysgammaglobulinemia, colitis, and rare clinical manifestations.

\section{HLH}

The mean age at first episode of HLH was 7.35 years (range, 2.0-19.0 years) in SAP-deficient and 6.5 years (range, 0.123.0 years $)$ in XIAP-deficient patients $(P=.89)$. The occur- rence of HLH in SAP-deficient (18 of 33, 55\%) and in XIAP-deficient (22 of 29,76\%, one unknown) patients did not differ significantly $(P=.112)$ (Figure 1A; Table 3). XIAPdeficient patients with null mutations (families $\mathrm{X} 1$ to $\mathrm{X} 7$ and X11) more frequently developed HLH (19 of 20, 95\%) compared with XIAP-deficient patients expressing non-null mutations (families $\mathrm{X} 8, \mathrm{X} 9$, and $\mathrm{X} 10 ; 3$ of $9,33 \%$; **P $=.0011$; supplemental Figure 1A).

Overall, 11 of the 33 SAP-deficient patients $(33 \%)$ and 5 of 30 the XIAP-deficient patients $(17 \%)$ succumbed to $\operatorname{HLH}(P=.1563)$. Among patients with HLH, HLH-associated lethality was significantly higher in SAP-deficient patients (11 of 18,61\%) than in XIAP-deficient patients (5 of $22,23 \%)(* P=.0230)$. HLH 
From bloodjournal.hematologylibrary.org at UNIVERSITAETSSPITAL on May 30, 2011. For personal use only. BLOOD, 3 FEBRUARY 2011 • VOLUME 117, NUMBER 5

Table 2. Characteristics of patients with mutations in XIAP (XLP-2)

\begin{tabular}{|c|c|c|c|c|c|c|c|c|c|c|}
\hline $\begin{array}{l}\text { Patient } \\
\text { ID* }\end{array}$ & $\begin{array}{c}X I A P \\
\text { mutation }\end{array}$ & $\begin{array}{l}\text { XIAP } \\
\text { protein }\end{array}$ & $\begin{array}{c}\text { HLH (age } \\
\text { in } \\
\text { years at } \\
\text { diagnosis) }\end{array}$ & $\begin{array}{c}\text { EBV at first } \\
\text { HLH }\end{array}$ & $\begin{array}{l}\text { HLH relapses } \\
\text { (age in years } \\
\text { at relapse) }\end{array}$ & $\begin{array}{l}\text { SM (age in } \\
\text { years at } \\
\text { diagnosis) }\end{array}$ & $\begin{array}{c}\text { Hypo- } \gamma \\
\text { (age in } \\
\text { years at } \\
\text { diagnosis) }\end{array}$ & $\begin{array}{l}\text { Chronic } \\
\text { colitis } \\
\text { (age in } \\
\text { years at } \\
\text { diagnosis) }\end{array}$ & $\begin{array}{c}\text { Other } \\
\text { manifestations } \\
\text { (age in years at } \\
\text { diagnosis) }\end{array}$ & $\begin{array}{c}\text { Outcome (age in } \\
\text { years) }\end{array}$ \\
\hline $\mathrm{X} 1.1$ & E99KfsX129 & & 5 & + & ? & ? & - & - & ? & Alive, well (8) \\
\hline $\mathrm{X} 1.2$ & E99KfsX129 & - & 5.3 & + & ? & $+(5)$ & - & - & ? & Alive, well (11) \\
\hline $\mathrm{X} 1.3$ & E99KfsX129 & & 2.5 & + & $?$ & $+(2.5)$ & + & - & $?$ & Alive, well, IVIG (14) \\
\hline $\mathrm{X} 1.4$ & E99KfsX129 & - & 7.8 & + & + & $+(6)$ & - & $+(4)$ & Cholangitis (23) & Alive, ileitis (23) \\
\hline $\mathrm{X} 1.5$ & E99KfsX129 & & 3 & + & + & $+(3)$ & - & - & - & Alive, well (30) \\
\hline $\mathrm{X} 1.6$ & E99KfsX129 & - & 0.8 & $-(\mathrm{HHV}-6+/-)$ & $+(\mathrm{EBV}+)$ & $+(1) \ddagger$ & $+(10)$ & - & - & HSCT (11), died (11) \\
\hline $\mathrm{X} 1.7$ & ND & & $1.5 \dagger$ & $?$ & + & $+(1.5) \ddagger$ & $+(42)$ & $+(41)$ & Cholangitis (41) & Died (42, colitis) \\
\hline$\times 2.1$ & I397FfsX414 & - & 1.2 & + & + & $+(1) \ddagger$ & - & - & - & $\begin{array}{c}\text { HSCT (1.6), died } \\
(d+13, \mathrm{HLH})\end{array}$ \\
\hline X3.1 & E118X & - & 23 & + & + & $+(22)$ & $+(22)$ & - & - & Alive, well, IVIG (39) \\
\hline X3.2 & ND & & 0.5 & $?$ & - & $?$ & $?$ & & - & $\operatorname{Died}(0.5, \mathrm{HLH})$ \\
\hline X3.3 & ND & & 20 & + & - & $?$ & $?$ & & - & Died $(20, \mathrm{HLH})$ \\
\hline X3.4 & E118X & - & - & NA & - & $+(7)$ & - & - & - & Alive, well, SM (10) \\
\hline$X 4.1$ & del. of exon 2 & - & 20 & + & $+(21, \mathrm{EBV}+)$ & $+(1) \ddagger$ & - & - & - & Alive, well (28) \\
\hline$X 4.2$ & del. of exon 2 & - & 10 & $?$ & $+(11, \mathrm{EBV}+)$ & $+(6) \ddagger$ & - & - & - & Alive, well (15) \\
\hline$\times 5.1$ & D130GfsX140 & - & 2.5 & + & $+(3.4-3.6)$ & $+(1)$ & - & - & - & HSCT (3.6), died (4) \\
\hline$\times 5.2$ & ND & & 0.1 & $?$ & - & $?$ & $?$ & - & - & Died $(0.1, \mathrm{HLH})$ \\
\hline$x 5.3$ & ND & & 3.5 & + & - & $?$ & $?$ & - & - & Died (3.5, HLH) \\
\hline $\mathrm{X} 6.1$ & $\mathrm{R} 238 \mathrm{X}$ & - & 1.7 & + & + & $+\ddagger$ & - & - & - & Alive, recurrent HLH (3) \\
\hline $\mathrm{X} 7.1$ & I397NfsX405 & - & 2.7 & + & $\begin{array}{r}+(3.2-3.5 \\
\text { EBV }+)\end{array}$ & $+(2.7)$ & - & - & - & $\begin{array}{l}\text { Alive, recurrent HLH } \\
\text { (3.5) }\end{array}$ \\
\hline $\mathrm{X} 8.1$ & E434AfsX457 & $+1-$ & 15.5 & + & - & - & - & - & - & Alive, well (16) \\
\hline X9.1 & G466X & $+1-$ & $8+$ & + & - & $+(8) \ddagger$ & $+(8) \S$ & - & - & Alive, well, SM (27) \\
\hline x9.2 & G466X & $+1-$ & - & NA & - & $+(21)$ & $+(21) \S$ & - & - & Alive, well, SM (30) \\
\hline $\mathrm{x} 9.3$ & G466X & $+1-$ & - & NA & - & $+(4) \ddagger$ & - & $+(12)$ & $\begin{array}{l}\text { Recurrent } \\
\text { infections }\end{array}$ & Alive, colitis (14) \\
\hline X9.4 & G466X & $+1-$ & - & NA & - & $+(22) \ddagger$ & $+(10) \S$ & - & $\begin{array}{l}\text { Chronic liver } \\
\text { failure (22) }\end{array}$ & $\begin{array}{l}\text { Died ( } 29 \text {, liver failure), } \\
\text { IVIG, }\end{array}$ \\
\hline X9.5 & G466X & $+1-$ & - & NA & - & - & - & - & - & Alive, well (39) \\
\hline X9.6 & ND & & - & NA & - & $?$ & $?$ & + & $?$ & Died (27, colitis) \\
\hline X9.7 & ND & & - & NA & - & $+\ddagger$ & $?$ & - & $\begin{array}{l}\text { Recurrent } \\
\text { infections }\end{array}$ & Died (52, pneumonia) \\
\hline $\mathrm{X} 10.1$ & T470S & + & $8+$ & $-(\mathrm{HSV}-1+)$ & - & - & $+(4) \S$ & - & $\begin{array}{l}\text { Cryptococcosis } \\
\text { (4) }\end{array}$ & Alive, well, IVIG (8) \\
\hline $\mathrm{X} 11.1$ & $\mathrm{R} 381 \mathrm{X}$ & - & $0.9 \dagger$ & - & NA & $+(0.6) \ddagger$ & - & - & - & HSCT (1.2), died (1.4) \\
\hline $\mathrm{X} 11.2$ & ND & & ? & ? & ? & ? & ? & $+(4)$ & ? & Died (4, colitis) \\
\hline
\end{tabular}

SM indicates recurrent splenomegaly or hepatosplenomegaly; Hypo- $\gamma$, hypogammaglobulinemia; ?, unknown; HSCT, hematopoietic stem cell transplantation; ND, not done; NA, not applicable; and del., deletion.

*Patient identification: X indicates XIAP deficiency, the first number corresponds to the family and the second to the individual patient; + indicates yes or positive; - , no or negative; and $+/-$, weakly positive.

†Diagnosed as incomplete HLH.

$\ddagger$ Recurrent splenomegaly or hepatosplenomegaly associated with intermittent fever, anemia, and cytopenia.

$\S$ With recurrent respiratory infections.

relapsed in 2 of 7 SAP-deficient HLH-survivors (29\%), whereas 11 of 14 XIAP-deficient HLH-survivors (79\%, 3 unknown) had $\geq 1$ relapse of $\operatorname{HLH}(P=.055)$.

Six of the 18 SAP-deficient patients with HLH (33\%) had proven neurologic involvement with mostly (5 of 6, 83\%) lethal outcome, whereas 2 of 22 of XIAP-deficient patients with HLH (9\%) had neurologic involvement with less mortality (1 of 2, 50\%).

EBV infection was the most-frequent identified trigger of the first HLH episode in the SAP-deficient (11 of 12, 92\%, 6 unknown) and XIAP-deficient (15 of 18, 83\%, 4 unknown) patients $(P=.63)$ (Table 3). Only PS13.1, PX1.6, PX10.1, and PX11.1 had a first HLH episode in the absence of a proven EBV-infection, whereas the EBV status of 6 SAP-deficient patients and 4 XIAP-deficient patients is not known. PX1.6 and PX4.2 subsequently experienced an HLH-relapse with positive EBV polymerase chain reaction. In 2 patients, herpes simplex virus type 1 (HSV-1) and human herpesvirus type 6 (HHV-6) were detected in the blood by polymerase chain reaction in the course of their first HLH episode. Of note, in several XIAP-deficient patients, other viruses than EBV were tested, including cytomegalovirus, parvovirus B19, HSV, HHV-6, HHV-8, HIV, human T-cell leukemia virus, adenovirus, and varicella-zoster virus. All were negative.

\section{Splenomegaly and incomplete forms of HLH}

Recurrent splenomegaly occurring in the absence of systemic HLH and often associated with fever and cytopenia (consisting of pancytopenia, bicytopenia, thrombocytopenia, and anemia) was frequently observed in XIAP-deficient patients (20 of 23, 87\%, 7 unknown), whereas it was only found in 2 of 29 SAP-deficient patients (7\%, 4 unknown; $* * * P<.0001$; Table 3). In 8 XIAPdeficient patients, episodes of splenomegaly occurred before they developed HLH and were the first clinical sign of the disease. Overall, although 3 patients with splenomegaly up to now did not 
A

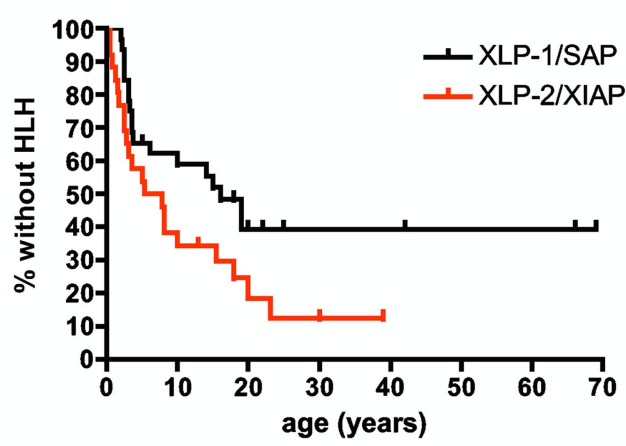

B

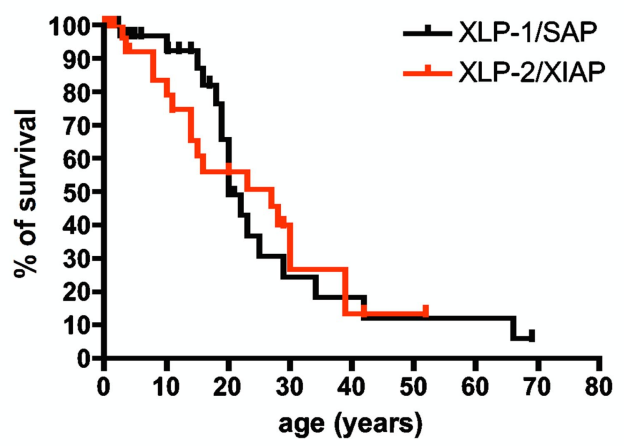

Figure 1. Comparison of HLH phenotypes and survival curves of SAP-deficient (XLP-1) and XIAP-deficient (XLP-2) patients. Kaplan-Meier survival curves were constructed on the basis of data presented in Table 1 and Table 2. Statistical analyses with log-rank tests. (A) Percentage of XLP-1/SAP and XLP-2/XIAP patients without HLH phenotype $(P=.099)$. (B) Overall survival curves for XLP-1/SAP and XLP-2/XIAP patients $(P=.948)$.

develop HLH, the others subsequently developed HLH within a period of time, varying from a few months to 19 years. In 2 XIAP-deficient patients, transient pancytopenia with splenomegaly was noticed after vaccinations against measles, mumps, and rubella or measles and rubella. Importantly, none of the XIAPdeficient patients developed B-cell lymphoproliferative disease.

PX4.1 underwent splenectomy at the age of 21 years, and histopathologic examination of the spleen showed reduced white pulp areas, and red pulp was extended with a mild fibrosis (supplemental Figure 2 top left). In the white pulp, most of the lymphocytes were $\mathrm{CD} 20^{+}$, whereas in the red pulp there was an accumulation of $\mathrm{CD}^{+}$T cells that were mostly $\mathrm{CD}^{+}$and cytotoxic (T-cell intracellular antigen- $1^{+}$; data not shown; supplemental Figure 2 bottom). Strikingly, features of hemophagocytosis were observed in the red pulp (supplemental Figure 2 upper right). Lymphocytes were negative for LMP-1 with very rare EBER ${ }^{+}$ cells, suggesting that the infiltration was not related to EBV infection (data not shown). Altogether, these observations strongly suggest that these lymphoproliferative manifestations can be regarded as incomplete or attenuated forms of HLH.

In addition, 3 XIAP-deficient patients had liver disease ( 2 patients with cholangitis and 1 patient with chronic liver failure). In 2 of the patients, the cholangitis was associated with colitis, which are known to overlap. ${ }^{18}$ For patient PX1.7, histopathologic examination of the liver showed granulomatous hepatitis in lobular areas with foci of macrophages around necrotic hepatocytes (supplemental Figure 3). Staining for LMP-1 was negative (data not shown). It is unclear whether these liver diseases should also be considered as an incomplete form of HLH.

Table 3. Comparison of XLP-1 and XLP-2 phenotypes

\begin{tabular}{|c|c|c|c|}
\hline & SAP-/Y, n (\%) & XIAP-/Y, n (\%) & $P^{\star}$ \\
\hline HLH & 18 of $33(55)$ & 22 of $29(76)$ & NS \\
\hline HLH relapses (/HLH-survivors) & 2 of 7 (29) & 11 of $14(79)$ & NS \\
\hline EBV at first HLH & 11 of $12(92)$ & 15 of $18(83)$ & NS \\
\hline Fatal HLH & 11 of $33(33)$ & 5 of $30(17)$ & NS \\
\hline Fatal HLH (/HLH patients) & 11 of $18(61)$ & 5 of $22(23)$ & .0230 \\
\hline Hypogammaglobulinemia & 14 of $21(67)$ & 8 of $24(33)$ & .0377 \\
\hline Lymphoma & 10 of $33(30)$ & 0 of $30(0)$ & .0010 \\
\hline $\begin{array}{l}\text { Cytopenias (in the absence of } \\
\text { full-blown HLH) }\end{array}$ & 4 of $33(12)$ & 11 of 21 (52) & .0020 \\
\hline $\begin{array}{l}\text { Splenomegaly (in the absence } \\
\text { of full-blown } \mathrm{HLH} \text { ) }\end{array}$ & 2 of $29(7)$ & 20 of $23(87)$ & $<.0001$ \\
\hline Hemorrhagic colitis & 0 of $33(0)$ & 5 of $30(17)$ & .0203 \\
\hline
\end{tabular}

${ }^{*}$ Calculated with Fisher exact tests.

\section{Lymphoma}

Ten of 33 SAP-deficient patients (30\%) and none of the 30 XIAPdeficient patients developed lymphoma (Tables 1-3; supplemental Figure $1 \mathrm{~B} ; * * * P=.001)$. Mean age at diagnosis of lymphoma was 15 years (range, 2-40 years). Diagnoses were non-Hodgkin lymphoma $(n=9)$, including EBV-positive Burkitt lymphoma $(n=6)$ and EBVnegative $(n=3)$. Lymphomas were localized in the ileocecal $(n=5)$, cerebral $^{19}(n=1)$, cervical $(n=2)$, and spinal $(n=2)$ regions, and for one the origin was not known. One patient (PS1.3) had a second lymphoma at the age of 30 years, 23 years after the first one, and one patient (PS15.3) had myelodysplasia.

\section{Dysgammaglobulinemia}

Hypogammaglobulinemia was documented in 14 SAP-deficient patients $(14$ of $21,67 \%)$ and in 8 XIAP-deficient patients (8 of 24 , $33 \%)(* P=.0377)$ (Tables $1-3)$. Thirty percent (10 of 33) of SAP-deficient patients and 13\% (4 of 30) of XIAP-deficient patients received intravenous immunoglobulin (IVIG) substitution $(P=.1357)$ (supplemental Figure 1C). Interestingly, hypogammaglobulinemia was transient in 2 of the 8 XIAP-deficient patients. PX3.1 was substituted with IVIG between the age of 23 and 35 years, currently, 4 years after stopping IVIG, immunoglobulin levels remain within the normal range, and the patient does not experience recurrent respiratory infections. Two XIAP-deficient patients developed hypergammaglobulinemia, with higher than normal IgA and IgM levels in PX9.3 and elevated $\operatorname{IgG}$ and $\operatorname{IgM}$ levels in PX11.1, respectively.

Severe infections were noted in several SAP- and XIAPdeficient patients with hypogammaglobulinemia before initiation of the IVIG substitution when treated. Ten of the 14 SAP-deficient and 4 of the 8 XIAP-deficient patients had recurrent respiratory tract infections. Rare severe infections caused by Haemophilus influenzae, Mycoplasma pneumoniae, Streptococcus pneumoniae, Staphylococcus aureus, and Cryptococcus neoformans were also observed in SAP- and XIAP-deficient patients (supplemental Table 1).

\section{Colitis}

Chronic colitis with hemorrhagic diarrheas or rectal bleeding or both evoking inflammatory bowel disease was observed in 5 of 30 XIAP-patients (17\%) but in none of 33 SAP-deficient patients (*P $=.0203$; Tables $1-3)$. In PX1.4, colitis initially responded to immunosuppressive treatment with corticosteroids and cyclosporine A. However, corticosteroids could not be withdrawn, and the 

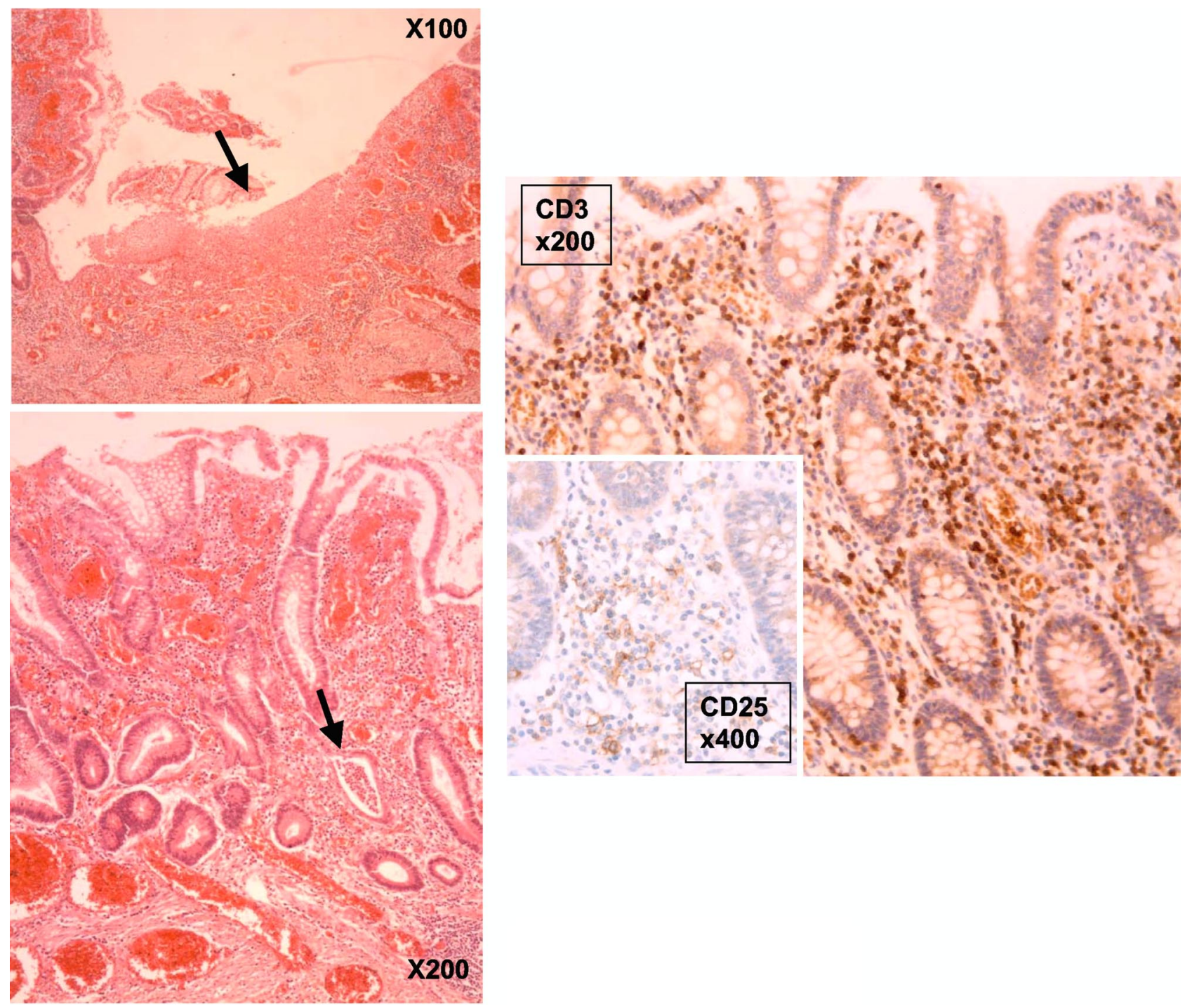

Figure 2. Histology of the large bowel of PX1.7 with XIAP deficiency. (Top left) On hematoxylin and eosin at low magnification ( $\times 100)$, a large ulceration is seen, indicated by an arrow. (Bottom left) Higher magnification $(\times 200)$ shows a massive polymorphic inflammatory infiltrate associated with a crypt abscess (indicated by the arrow). (Central right) Immunostaining with anti-CD3 shows frequent lymphoid T cells (on the right, $\times 200$ ), some of them express the activation marker CD25 ( $\times 400$, inset).

addition of azathioprine could not prevent the recurrence of symptoms. Anti-tumor necrosis factor- $\alpha \mathrm{mAb}$ treatment (infliximab) provided partial improvement. Recently, a colectomy was performed, but the patient now has terminal ileitis. In PX1.7, severe hemorrhagic colitis was associated with portal hypertension and massive gastroduodenal bleeding that lead to death of this patient. Patients PX9.6 and PX11.2 also suffered from chronic colitis and most probably died of intestinal hemorrhage.

Histopathologic examination of intestinal mucosa biopsy specimens was performed in 3 patients, PX1.4, PX1.7, and PX9.3. Representative images are shown in Figure 2. Hemorrhagic ulcerations of the colon associated with mononuclear infiltration consisting of lymphoid cells and plasma cells in the lamina propria were observed (Figure 2 left top). Crypt architecture was mostly preserved, except for rare crypt abscesses (Figure 2, left bottom), but frequent apoptotic crypt cells were seen (supplemental Figure 4). The lymphoid cells were mostly $\mathrm{CD}^{+}$and $\mathrm{CD} 8^{+}$with some lymphocytes expressing CD25 with numerous eosinophils (in PX1.4) (Figure 2; supplemental Figure 4). $\mathrm{CD} 20^{+}$cells were rare, EBER staining was negative (not shown), and there was no granuloma formation. Microbiologic cultures were negative in all 3 cases.

\section{Rare clinical manifestations}

Rare clinical features (supplemental Table 1), each observed in 1 SAP-deficient patient, were hemolytic uremic syndrome associated with HLH, vasculitis, and arthritis. Clinical features, each observed in 1 XIAP-deficient patient, were Kawasaki syndrome and psoriasis. Additional infections in patients without hypogammaglobulinemia were caused by Pseudomonas aeruginosa (1 SAPdeficient patient), recurrent measles (1 XIAP-deficient patient), and HSV-(1 XIAP-deficient patient). Of note, 2 SAP-deficient patients (PS3.1 and PS3.2) had chronic gastritis. ${ }^{20}$

\section{Survival and outcome}

Sixteen of 33 SAP-deficient patients and 12 of 30 XIAP-deficient patients died at a mean age of 11 years (range, 2-69 years) and 16 years (range, 0.1-52 years), respectively. Survival rates did not differ between both patient groups $(P=.93$; Figure $1 \mathrm{~B})$, and the proportions of whom reached adulthood (age $\geq 16$ years) were similar in both groups (17 of 33 SAP-deficient patients [52\%] and 
13 of 30 XIAP-deficient patients [43\%]). Mortality was related to HLH (11 SAP- and 5 XIAP-deficient patients), lymphoma (2 SAPdeficient patients), myelodysplasia (1 SAP-deficient patient), colitis (3 XIAP-deficient patients), hepatitis (1 XIAP-deficient patient), complications of hematopoietic stem cell transplantation (2 SAPand 4 XIAP-deficient patients), and pneumonia (1 XIAP-deficient patient). Mean age at last follow-up was 24.9 years (range, 10-66 years) for SAP-deficient patients and 17.5 years (range, 0.7- 39 years) for XIAP-deficient patients. Among the surviving 17 SAP-deficient patients, 4 are well without any treatment, 10 receive IVIG substitution, 2 are currently treated for a lymphoma, and 1 had successful hematopoietic stem cell transplantation. Among the surviving 17 XIAP-deficient patients, 10 are well without any treatment (among them 3 with splenomegaly), 2 received recently anti-CD20 antibody treatment because of EBVrelated HLH, 2 are under IVIG substitution, 1 has terminal ileitis after colectomy, 1 has colitis treated with mesalazine and azathioprine, and 1 has recurrent HLH treated with cyclosporine A and dexamethasone. One XIAP-deficient and 2 SAP-deficient patients have never developed clinical signs and are considered to be asymptomatic.

\section{Discussion}

We report the first comparison of the clinical phenotypes of SAPand XIAP-deficient patients. The present study was based on a retrospective analysis with data from medical records on 33 SAPand 30 XIAP-deficient patients. The relatively small size of both cohorts obviously implies that data should be interpreted with caution.

The overall clinical phenotypes of the affected persons matched with the phenotypes previously reported..$^{2,7,9,21}$ In accordance to previous studies, we did not observe any genotype-phenotype correlation in the SAP-deficient patients. However, in our cohort of XIAP-deficient patients, we noticed that XIAP-deficient patients carrying non-null mutations had a tendency to be less prone to develop HLH by contrast to patients with null mutations. However, other genetic or environmental factors may contribute to the variety of phenotypes observed in XLP-1 and XLP-2.

HLH occurred both in SAP- and in XIAP-deficient patients but with more frequent neurologic involvement and fatal outcome in SAP-deficient patients than in XIAP-deficient patients. Splenomegaly often associated with cytopenia and fever was more frequent in XIAP-deficient patients than in SAP-deficient patients. Histologic analysis of one spleen showed accumulation of activated $\mathrm{CD} 8^{+} \mathrm{T}$ cells and hemophagocytosis without $\mathrm{EBV}^{+}$cells. These symptoms probably represent incomplete forms of HLH. In addition, HLH relapses seemed to be more common in XIAP- than in SAP-deficient patients who survived HLH. Together, these findings suggest that HLH has a less severe disease course in XIAP- deficient patients than in SAP-deficient patients.

In most of the patients from both groups, the trigger of HLH was an EBV infection ( $>80 \%)$; EBV may favor HLH by eliciting a potent CD8 T-cell response. It is also postulated that SAP and possibly XIAP are associated with activation pathways that are more important in triggering selective cytotoxicity toward B cells. ${ }^{22-}$ $27 \mathrm{HLH}$ in most hereditary conditions such as FHL, Griscelli syndrome type II, and Chediak-Higashi syndrome shares common pathophysiologic mechanisms, that is, global impaired cytotoxicity responses that lead to the inability of effector lymphocytes to kill infected cells and antigen-presenting cells. ${ }^{28}$ In mice and humans, SAP-deficient CD8 ${ }^{+} \mathrm{T}$ and NK cells exhibit defective cytotoxicity responses caused by abnormal functions of SLAM receptors. ${ }^{29}$ This could explain the occurrence of HLH in SAP-deficient patients. ${ }^{22-27}$ In contrast, NK-cell and T-cell cytotoxic responses appear to be preserved in XIAP-deficient patients ${ }^{7,9}$ (C. Synaeve and S.L., unpublished data, 2009 and 2010). This might account for the lower severity of the HLH in the XIAP deficiency. Hence, the precise immune defects responsible for HLH in XIAP deficiency remain to be elucidated.

Only XIAP-deficient patients were at risk for chronic colitis with often a lethal outcome. This phenotype seems that is may be even worse than HLH, because the mortality in the group of patients with colitis ( 3 of 5) has a tendency to be higher than in the group with HLH (5 of 22). Histopathologic analysis of intestinal mucosal biopsy specimens showed an inflammatory process with an accumulation of activated $\mathrm{T}$ cells (and eosinophils in one patient) that could evoke inflammatory bowel disease. Interestingly, a recent report indicates that XIAP is involved in nucleotidebinding oligomerization domain containing 2 (NOD2) activation which is an intracellular pattern recognition receptor of the NOD-like receptor family. ${ }^{30}$ Importantly, NOD2 is a key susceptibility gene for Crohn disease. ${ }^{31}$ Thus, defects in XIAP might lead to defective NOD2 responses as an additive risk factor for colitis in some of these patients. Of note, however, NOD2 was sequenced in 2 XIAP-deficient patients with colitis, and none had the genotype shown to be a risk factor for Crohn disease (J.P. Hugot and S.L., unpublished data, June 2006).

One striking difference between XLP-1 and XLP-2 was that only SAP-deficient patients developed lymphoma, although it could not be formally excluded that XIAP-patients might develop lymphomas in the future. In SAP-deficiency, the occurrence of lymphomas may be explained by defective immunosurveillance of hematopoietic cells, resulting from alterations in SLAM receptor-mediated NK- and T-cell cytotoxicity responses, ${ }^{22-24,26}$ but also by the proapoptotic functions that have been assigned to SAP. ${ }^{32,33}$

Another common finding shared by XLP-1 and XLP-2 is the hypogammaglobulinemia. Interestingly, 2 XLP-2 patients recovered from hypogammaglobulinemia, which so far seems not to be the case for XLP-1 patients. Numerous studies in mice and humans have documented that impaired antibody production found in XLP-1 resulted from a block in germinal center formation, leading to defects in the differentiation of Ig-isotype-switched memory B cells. ${ }^{34-36}$ In most of the XIAP-deficient patients, Ig-isotypeswitched memory B cells are not found to be decreased ${ }^{7}$ (S. Siberil and S.L., unpublished data, 2008 and 2009). In XIAP deficiency, hypogammaglobunemia could be the consequence of increased activation-induced cell death of B cells, a hypothesis that needs to be tested.

In conclusion, the present comparison of the clinical features of SAP- and XIAP-deficient patients shows that SAP deficiency and XIAP deficiency share a main phenotype, that is, EBV-induced HLH. This similarity raises the possibility of a functional/ molecular link between SAP and XIAP proteins. Alternatively, impairment of 2 independent pathways, both important in EBV immunity, could lead to a shared phenotype. Nevertheless, we also demonstrate that XLP-1 and XLP-2 can be distinguished on several clinical aspects, which could be helpful for diagnosis and therapeutic decisions. 


\section{Acknowledgments}

We thank the patients and their families for cooperation.

This work was supported by grants from Inserm, the Agence Nationale de la Recherche (ANR-05-MIM-010 and ANR-08-MIEN012-01; S.L.), the XLP Research Trust (United Kingdom; S.L.), the Czech Ministery of Health (NS 10 480-3; E.M.), the Fondazione Ettore e Valeria Rossi (J.P.S.), and the Walter und Gertrud Siegenthaler Stiftung (J.P.S.). S.L. is a senior scientist of Center National de la Recherche Scientifique (CNRS, France).

\section{Authorship}

Contribution: J.P.S. collected and analyzed the data and participated in study design, writing of the report, and patients' care; D.C. performed the immunohistochemistry experiments and analyzed histopathologic findings; F.H. participated in histopathologic analysis and writing of the report; C.L., N.L., and S.R. realized gene sequencing and protein expression tests; G.S.B. participated in data analysis; A.F. contributed to study design, data analysis, writing of the report, and patients' care; S.L. coordinated the study collected the data and contributed to sequencing, expression tests, data analysis, and wrote the report. The other authors provided and collected the clinical data on patients' status and contributed to the data analysis and patients' care.

Conflict-of-interest disclosure: The authors declare no competing financial interests.

Correspondence: Sylvain Latour and Alain Fischer, Laboratoire du Développement Normal et Pathologique du Système Immunitaire, Inserm U768, Hôpital Necker-Enfants Malades, F-75015 Paris, France; e-mail: sylvain.latour@inserm.fr.

\section{References}

1. Purtilo DT, Cassel C, Yang JP. Letter: fatal infectious mononucleosis in familial lymphohistiocytosis. N Engl J Med. 1974;291(14):736.

2. Purtilo DT, Cassel CK, Yang JP, Harper R. $\mathrm{X}$-linked recessive progressive combined variable immunodeficiency (Duncan's disease). Lancet. 1975;1(7913):935-940.

3. Seemayer TA, Gross TG, Egeler RM, et al. X-linked lymphoproliferative disease: twenty-five years after the discovery. Pediatr Res. 1995;38(4):471-478.

4. Henter JI, Horne A, Arico M, et al. HLH-2004: Diagnostic and therapeutic guidelines for hemophagocytic lymphohistiocytosis. Pediatr Blood Cancer. 2007;48(2):124-131.

5. Sayos J, Wu C, Morra M, et al. The X-linked lymphoproliferative-disease gene product SAP regulates signals induced through the co-receptor SLAM. Nature. 1998;395(6701):462-469.

6. Coffey AJ, Brooksbank RA, Brandau O, et al. Host response to EBV infection in X-linked lymphoproliferative disease results from mutations in an SH2-domain encoding gene. Nat Genet. 1998; 20(2):129-135.

7. Rigaud S, Fondaneche MC, Lambert N, et al. XIAP deficiency in humans causes an X-linked lymphoproliferative syndrome. Nature. 2006;444 (7115):110-114.

8. Zhao M, Kanegane H, Ouchi K, Imamura T, Latour S, Miyawaki T. A novel XIAP mutation in a Japanese boy with recurrent pancytopenia and splenomegaly. Haematologica. 2009;95(4):688-689.

9. Marsh RA, Madden L, Kitchen BJ, et al. XIAP deficiency: a unique primary immunodeficiency best classified as X-linked familial hemophagocytic lymphohistiocytosis and not as X-linked lymphoproliferative disease. Blood. 2010;7(116):10791082.

10. Gaspar HB, Sharifi R, Gilmour KC, Thrasher AJ. X-linked lymphoproliferative disease: clinical, diagnostic and molecular perspective. Br J Haematol. 2002;119(3):585-595.

11. Nichols KE, Ma CS, Cannons JL, Schwartzberg PL, Tangye SG. Molecular and cellular pathogenesis of X-linked lymphoproliferative disease. Immunol Rev. 2005;203:180-199.

12. Grierson HL, Skare J, Hawk J, Pauza M, Purtilo DT. Immunoglobulin class and subclass deficiencies prior to Epstein-Barr virus infection in males with X-linked lymphoproliferative disease. Am J Med Genet. 1991;40(3):294-297.
13. Dutz JP, Benoit L, Wang X, et al. Lymphocytic vasculitis in $\mathrm{X}$-linked lymphoproliferative disease. Blood. 2001;97(1):95-100.

14. Ma CS, Nichols KE, Tangye SG. Regulation of cellular and humoral immune responses by the SLAM and SAP families of molecules. Annu Rev Immunol. 2007;25:337-379.

15. Eckelman BP, Salvesen GS, Scott FL. Human inhibitor of apoptosis proteins: why XIAP is the black sheep of the family. EMBO Rep. 2006;7(10): 988-994.

16. Galban S, Duckett CS. XIAP as a ubiquitin ligase in cellular signaling. Cell Death Differ. 2009;17(1): 54-60.

17. Verhelst $H$, Van Coster R, Bockaert N, et al. Limbic encephalitis as presentation of a SAP deficiency. Neurology. 2007;69(2):218-219.

18. Knight $C$, Murray KF. Hepatobiliary associations with inflammatory bowel disease. Expert Rev Gastroenterol Hepatol. 2009;3(6):681-691.

19. Hervier B, Latour S, Loussouarn D, et al. An atypical case of $X$-linked lymphoproliferative disease revealed as a late cerebral lymphoma. J Neuroimmunol. 2010;218(1-2):125-128.

20. Rougemont AL, Fournet JC, Martin SR, et al. Chronic active gastritis in X-linked lymphoproliferative disease. Am J Surg Pathol. 2008;32(2): 323-328.

21. Sumegi J, Huang D, Lanyi A, et al. Correlation of mutations of the SH2D1A gene and Epstein-Barr virus infection with clinical phenotype and outcome in X-linked lymphoproliferative disease. Blood. 2000;96(9):3118-3125.

22. Dong Z, Cruz-Munoz ME, Zhong MC, Chen R, Latour S, Veillette A. Essential function for SAP family adaptors in the surveillance of hematopoietic cells by natural killer cells. Nat Immunol. 2009;10(9):973-980.

23. Bloch-Queyrat C, Fondaneche MC, Chen R, et al. Regulation of natural cytotoxicity by the adaptor SAP and the Src-related kinase Fyn. J Exp Med. 2005;202(1):181-192.

24. Parolini S, Bottino C, Falco M, et al. X-linked lymphoproliferative disease. 2B4 molecules displaying inhibitory rather than activating function are responsible for the inability of natural killer cells to kill Epstein-Barr virus-infected cells. J Exp Med. 2000;192(3):337-346.

25. Dupre L, Andolfi G, Tangye SG, et al. SAP con- trols the cytolytic activity of CD8 $+\mathrm{T}$ cells against EBV-infected cells. Blood. 2005;105(11):43834389.

26. Sharifi R, Sinclair JC, Gilmour KC, et al. SAP mediates specific cytotoxic T-cell functions in $\mathrm{X}$-linked lymphoproliferative disease. Blood 2004;103(10):3821-3827.

27. Hislop AD, Palendira U, Leese AM, et al. Impaired Epstein-Barr virus-specific CD8 + T cell function in X-linked lymphoproliferative disease is restricted to SLAM family positive B cell targets. Blood. Blood. 2010;116(17):3249-3257.

28. Fischer A, Latour S, de Saint Basile G. Genetic defects affecting lymphocyte cytotoxicity. Curr Opin Immunol. 2007;19(3):348-353.

29. Veillette A, Dong Z, Perez-Quintero LA, Zhong MC, Cruz-Munoz ME. Importance and mechanism of 'switch' function of SAP family adapters. Immunol Rev. 2009;232(1):229-239.

30. Krieg A, Correa RG, Garrison JB, et al. XIAP mediates NOD signaling via interaction with RIP2. Proc Natl Acad Sci U S A. 2009;106(34):1452414529.

31. Hugot JP, Chamaillard M, Zouali $\mathrm{H}$, et al. Association of NOD2 leucine-rich repeat variants with susceptibility to Crohn's disease. Nature. 2001; 411(6837):599-603.

32. Snow AL, Marsh RA, Krummey SM, et al. Restimulation-induced apoptosis of T cells is impaired in patients with X-linked lymphoproliferative disease caused by SAP deficiency. J Clin Invest. 2009;119(10):2976-2989.

33. Chen G, Tai AK, Lin M, Chang F, Terhorst C, Huber BT. Signaling lymphocyte activation molecule-associated protein is a negative regulator of the CD8 T cell response in mice. J Immunol. 2005;175(4):2212-2218.

34. Crotty S, Kersh EN, Cannons J, Schwartzberg PL, Ahmed R. SAP is required for generating long-term humoral immunity. Nature. 2003;421(6920):282-287.

35. Qi H, Cannons JL, Klauschen F, Schwartzberg PL, Germain RN. SAP-controlled T-B cell interactions underlie germinal centre formation. Nature. 2008; 455(7214):764-769.

36. Ma CS, Hare NJ, Nichols KE, et al. Impaired humoral immunity in X-linked lymphoproliferative disease is associated with defective IL-10 production by CD4+ T cells. J Clin Invest. 2005; 115(4):1049-1059. 